\title{
Literatura e formação humanística em medicina: experimento do Laboratório de Humanidades da EPM/UNIFESP
}

\author{
Literature and humanistic education in medicine: the \\ experiment of the Laboratory of Humanities of EPM/UNIFESP
}

\author{
Dante Marcello Claramonte Gallian
}

Gallian DMC. Literatura e formação humanística em medicina: o experimento do Laboratorio de Humanidades da EPM/ UNIFESP / Liiterature and humanistic education in medicine: the experiment of the Laboratory of Humanities of EPM/ UNIFESP. Rev Med (São Paulo). 2012 jul.-set.;91(3):174-7.

RESUMO: Este artigo descreve, a partir da experiência com uma atividade educacional desenvolvida com alunos de graduação e pós-graduação da EPM-UNIFESP, o Laboratório de Humanidades, a forma como a leitura e discussão de clássicos da literatura universal pode contribuir para o processo de formação humanística e humanização de futuros médicos e profissionais da saúde em geral. Fundamentado na perspectiva teórica das humanidades e na observação empírica do fenômeno educacional, este estudo aponta a experiência estética e reflexiva a partir da literatura como forma privilegiada de promover a humanização no contexto educacional.

DESCRITORES: Educação médica; Humanidades; Ciências humanas/ética; Ciências humanas/educação; Humanização da assistência; Humanismo. Atividades humanas/ética; Literatura.
ABSTRACT: Based on the experience of an educational activity for undergraduate and post graduate students from EPM-UNIFESP, the Laboratory of Humanities, this article aim to describe the way as reading and discussion of literature classics can give humanistic contributions for the medical education. Grounded in the humanities theoretical background and in the empirical observation of educational phenomena, this study shows that aesthetical and reflective experience could be a privileged form to promote "humanization" in the medical education context.

KEYWORDS: Education, medical; Humanities/ethics; Humanities/education; Humanization of assistance; Humanism; Human activities/ethics; Literature.

Docente e Diretor do Centro de História e Filosofia das Ciências da Saúde - CeHFi da EPM/UNIFESP.

Endereço para correspondencia: Dante Marcello C. Gallian. Rua Botucatu, 750 - Vila Clementino, São Paulo, SP, CEP: 04023-900. E-mail: dante.cehfi@epm.br 
Em uma de suas obras mais recentes, que repercutiu de maneira contundente no meio acadêmico e cultural, Tzevtan Todorov ${ }^{3}$, fazendo uma espécie de mea culpa intelectual, pondera como o desenvolvimento prodigioso da crítica e da teoria literária ao longo do último século acabou "seqüestrando" a grande literatura do público comum, tornando-a quase inacessível. A partir das leituras e interpretações autorizadas e autoritárias da crítica especializada, oficializadas e impostas pelos aparelhos ideológicos nas esferas educacionais e culturais, as grandes obras, os clássicos da literatura universal, passaram a ser território de especialistas e iniciados. Tal empoderamento determinou, segundo o critico búlgaro, um afastamento de uma das mais importantes e poderosas fontes de humanização do homem moderno, o que vem contribuindo fortemente para o radical empobrecimento cultural e ético que se verifica em nossos tempos.

Libertar a literatura do "espartilho asfixiante" das criticas formalistas é, portanto, segundo Todorov, o caminho para devolver-lhe seu caráter humanista, resgatando o seu papel de fornecer às pessoas "uma verdade e uma capacidade de estar no mundo." É preciso lembrar as pessoas de que os grandes escritores escreveram suas obras para serem lidas não por críticos e especialistas acadêmicos, mas para todos os homens e mulheres que buscam na literatura uma luz, um consolo, um caminho de encontro e compreensão de si mesmos.

Há pouco mais de oito anos, de maneira absolutamente espontânea, começamos, na Escola Paulista de Medicina (EPM) da UNIFESP, a promover uma atividade que vem possibilitando a realização dessa experiência libertadora e humanizadora reivindicada por Todorov.

Com uma pequena turma de estudantes que haviam cursado conosco a disciplina eletiva de História da Medicina e com os quais havíamos lido e discutido textos clássicos da arte médica, iniciamos um grupo de leitura e discussão de obras literárias, num horário extra classes. Começando com contos ou livros pequenos, aos poucos o grupo cresceu em número e ambição, passando a "enfrentar" obras clássicas de grande porte, como "Dom Quixote" de Cervantes, "A Tempestade" de Shakespeare, ou "O Idiota" de Dostoievski. Foi assim que nasceu o Laboratório de Humanidades do Centro de História e Filosofia das Ciências da Saúde (CeHFI) da EPMUNIFESP.

A descoberta de que "qualquer um", ou seja, de que alguém que não fosse um especialista ou iniciado, ou nem mesmo estudante da área de Letras ou Ciências Humanas, pudesse ler, entender e, mais do que tudo, vibrar com os clássicos da literatura universal, foi fonte de grande admiração e alegria. Mais do que isso, entretanto, aquele novo "experimento" realizado em nosso peculiar laboratório, acabou por se revelar um inusitado e poderoso meio de formação, de humanização - elemento tão necessário quanto discutido e almejado no âmbito da medicina e das ciências da saúde em geral.

Verificou-se que a experiência desencadeada pela leitura e, mais ainda, pelo compartilhamento das leituras nas reuniões semanais do Laboratório de Humanidades, não apenas atendiam ao desejo e necessidade de contato com aquelas obras, como também os estimulava, suscitando a elaboração e expressão de afetos, sentimentos, idéias, por parte de cada participante. Um autêntico processo de transformação, de "ampliação da esfera do ser", para usar uma expressão tomada de empréstimo de Montesquieu por Teixeira Coelho², é testemunhado por muitos do que participam dessa experiência laboratorial com os clássicos da literatura.

O "experimento" laboratorial nos ensina: a literatura, a narrativa literária, nos interpela primeiramente como acontecimento estético, no sentido original da palavra grega aestesis (despertar, inverso de anestesis, anestesiar) mobilizando-nos afetivamente - gostamos de ouvir e ler histórias porque elas nos afetam; nos trazem prazer, alegria, comoção, ódio, terror... Ou seja, a literatura nos "pega" porque nos lembra que estamos vivos e que temos um coração e um corpo para sentir.

Em segundo lugar, a experiência laboratorial mostra que este despertar afetivo produzido pelo acontecimento estético que a leitura proporciona desencadeia um poderoso movimento reflexivo; ou seja, a tempestade de afetos, sentimentos, idéias suscitadas pela leitura exige um espaço de escape, de expressão. A forma e a dinâmica do Laboratório de Humanidades, ao proporcionar este espaço, através de seus encontros presenciais semanais e virtuais permanentes, permite não apenas que esses conteúdos, impressões e opiniões sejam expressos, mas também elaborados, confrontados, reestruturados, enfim, trabalhados. Assim, sem deixar de ser um espaço de comunicação de sensações e afetos, o Laboratório se constitui, naturalmente, num espaço de trabalho do pensamento, de reflexão, de elaboração filosófica no sentido mais radical e primitivo desta expressão, ou seja, de mergulho e encontro com as questões essenciais da existência humana.

Tal acontecimento não é mérito exclusivo da dinâmica laboratorial. Na verdade, o LabHum (como é familiarmente chamado o Laboratório de Humanidades) apenas propicia e potencializa uma virtude que é da própria literatura. Como apontava Todorov $^{3}$, a literatura caracterizou-se historicamente por proporcionar sempre o acesso "a uma certa verdade sobre o mundo e sobre o homem". "Que 
Gallian DMC. Literatura e formação humanística em medicina.

melhor introdução à compreensão das paixões e dos comportamentos humanos do que uma imersão na obra dos grandes escritores que se dedicam a essa tarefa há milênios?" - pergunta-nos o autor de A Literatura em Perigo (p.36) ${ }^{3}$.

Corroborando as considerações de Todorov ${ }^{3}$, outro crítico contemporâneo, membro do Collège de France, para quem também "é tempo de se fazer novamente o elogio da literatura, de protegê-la da depreciação na escola e no mundo", Antoine Compagnon ${ }^{1}$, em sugestivo ensaio intitulado Literatura para Quê?, seguindo a trilha já palmilhada por Ítalo Calvino, lembra que

as coisas que a literatura pode procurar e ensinar são pouco numerosas mas insubstituíveis: a maneira de ver o próximo e si mesmo, de atribuir valor às coisas pequenas ou grandes, de encontrar as proporções da vida, e o lugar do amor nela, e sua força e seu ritmo, e o lugar da morte, a maneira de pensar e de não pensar nela, e outras coisas necessárias e difíceis, como a rudeza, a piedade, a tristeza, a ironia, o humor (p.45) ${ }^{1}$.

Pouco numerosas mas insubstituíveis: as questões essências da existência humana, enfim. Questões inevitáveis e que se impõem a todo aquele se vê inquieto diante da experiência do ser. Questões que vêm sendo formuladas e enfrentadas desde tempos imemoriais na história da humanidade e que na tradição ocidental foram sendo abarcadas e reivindicadas pela filosofia. Questões essenciais que, na medida em que foram sendo "aprisionadas" primeiramente pela filosofia e posteriormente "desqualificadas" ou "requalificadas" pelas ciências, foram ficando, paulatinamente, distantes, exotéricas, abstratas e, tal como o ocorreu com a própria literatura, "proibidas" para as pessoas comuns.

Desta forma, o "resgate da literatura" defendido por Todorov e Compagnon", representa também o resgate da capacidade de pensar, de refletir sobre essas grandes questões de uma forma muito mais real, concreta, "interna", enfim, humanizada. Isso porque, como afirma Compagnon (p.33)1, "com a literatura, o concreto se substitui ao abstrato e o exemplo à experiência para inspirar as máximas gerais ou, ao menos, uma conduta em conformidade com tais máximas".

Possibilitando acessar uma experiência sensível e um conhecimento moral que seria difícil, até mesmo impossível de se adquirir através da leitura dos tratados filosóficos e científicos, a literatura contribui de forma insubstituível não apenas para nossa "educação sentimental", como também para nossa formação ética, tanto prática como especulativa.
Citando Zola, Compagnon ${ }^{1}$ afirma: "A verdade é que as obras-primas do romance contemporâneo dizem muito mais sobre o homem e sobre a natureza do que graves obras de Filosofia, de História e de Crítica" (p.26).

\section{E complementa:}

Exercício de reflexão e experiência de escrita, a literatura responde a um projeto de conhecimento do homem e do mundo. Um ensaio de Montaigne, uma tragédia de Racine, um poema de Baudelaire, o romance de Proust nos ensinam mais sobre a vida do que longos tratados científicos. Tal foi por muito tempo a justificativa da leitura ordinária e a premissa da erudição literária. A ciência as desqualificou? É o que parece.

Fundamentado e lastreado por essa "virtude filosófica" própria da literatura, a experiência do Laboratório de Humanidades nada mais faz, portanto, do que dinamizar e potencializar essa qualidade ontológica dos grandes clássicos, gerando um espaço de autêntica reflexão, descoberta e humanização. Assim, da experiência estética da leitura compartiIhada nasce, no âmbito da dinâmica laboratorial, um movimento amplificado de reflexão e interpretação que, sem se estruturar numa tese ou conclusão fechada, permite a elaboração de um conhecimento; um conhecimento que é ao mesmo tempo individual e coletivo, subjetivo e objetivo, e que se estabelece como uma nova visão sobre "a verdade do mundo e do homem". Visão esta que não apenas responde à dimensão dos anseios de uma ética especulativa, mas também de uma ética prática, pois como tem sido possível observar também, a experiência com a literatura no Laboratório acaba por afetar não apenas o plano dos sentimentos e da inteligência, mas também da vontade. Diante de toda essa mobilização gerada pela experiência estética não é possível evitar um novo posicionamento no âmbito ético.

E aqui confirma-se mais uma vez a constatação não só teórica mas também histórica de Compagnon': "Seu poder emancipador [da literatura] continua intacto, o que nos conduzirá por vezes a querer derrubar os ídolos e a mudar o mundo, mas quase sempre nos tornará simplesmente mais sensíveis e mais sábios, em uma palavra, melhores".

Tal é o resultado do experimento que se tem verificado no Laboratório de Humanidades ao longo desses últimos anos. Movimento de sensibilização e de mobilização no plano intelectual e ético; humanização efetiva, com efetivo impacto no âmbito educacional e profissional no campo da saúde, como vêm atestando os estudos que estão sendo realizados*

\footnotetext{
* Para uma visão mais abrangente a respeito dos projetos de pesquisa que vêm sendo realizados sobre o Laboratório de Humanidades, contando inclusive com financiamento da FAPESP e de instituições internacionais como o King's College London, UK. Available from: http://www.unifesp.br/centros/cehfi/portal/index.php?option=com_content\&view=section\&id=4\&ltemid=2).
} 


\section{REFERÊNCIAS}

1. Compagnon A. Literatura para quê? Belo Horizonte: Editora UFMG; 2009.

2. Teixera Coelho. A cultura como experiência. In: Ribeiro RJ, organizador. Humanidades; um novo curso na USP.
São Paulo: EDUSP; 2001. p.65-101.

3. Todorov T. A literatura em perigo. São Paulo: Difel; 2007. 